\title{
AC 2012-5044: INJECTING THE REAL WORLD INTO THE CAPSTONE DESIGN EXPERIENCE
}

\section{Mr. David B. Kanipe, Texas A\&M University}

A native Texan, David Kanipe attended Texas A\&M University beginning in Sept. 1966, where he received a bachelor's of science degree in aerospace engineering in May 1970, followed by an M.S. in aerospace engineering in Aug. 1971. He accepted a position with NASA at the Manned Spacecraft Center in Houston in Nov. 1972. He served as the Chief of the Aeroscience and Flight Mechanics Division in the Engineering Directorate at the Johnson Space Center until retirement in Dec. 2010. A month after his arrival at NASA, the last Apollo mission, Apollo 17, was launched. Obviously, that was exciting, but in terms of his career, the almost simultaneous commencement of the Space Shuttle Program in Nov. 1972 was to have far more impact. As a result, Kanipe was able to begin his career working on what he says was the most interesting project he could possibly imagine: the Space Shuttle. Kanipe became the Deputy Branch Chief of the Aerodynamics Branch in May 1990, and in March 1996 was appointed as Chief of the GN\&C Analysis and Design Branch. Subsequently, he became the Deputy Chief of the Aeroscience and Flight Mechanics Division in Dec. 1998 and was selected as Chief of the Aeroscience and Flight Mechanics Division in the Engineering Directorate at the Johnson Space Center in Jan. 2001. Subsequently, due to his 38 years of experience in the Space Program covering many projects and programs, the Head of the Aerospace Engineering Department at Texas A\&M University asked him to come to A\&M and teach a senior capstone design course in spacecraft design. As he puts it, he spent 38 years at NASA preparing to teach this course. 


\section{Injecting the Real World into the Capstone Design Experience}

The engineering community, in many ways, has remained unchanged from previous decades: it is a fast paced environment that, above all else, requires technically proficient engineers. There are however, at least two aspects of engineering that have changed significantly in the past 10-20 years. There is now a much larger dependence on teamwork and the principles of systems engineering are becoming more commonplace in the engineering work place. The student who graduates well-grounded in the technical skills of his/her major will always be in demand. However, in addition to the same technical capabilities, the student who graduates with a clear understanding of the systems engineering process and views teamwork as the standard way of doing business will automatically enter the workforce with a distinct advantage. Thus, to be relevant in today's world, the Capstone Design experience must, as accurately as possible, reflect the environment the students will encounter when they report for work. Through the application of systems engineering processes to guide the utilization of the technical skills they spent the first three years of their undergraduate life learning, the students will gain a much better appreciation for the design process and its interdependencies, as well as the strengths, and limitations, of teamwork. In addition, this approach allows the students with true leadership capability to rise to the surface. In many cases, these students may have not even realized they had leadership potential.

Introduction

While most Capstone Design courses necessarily follow standard industry processes and guidelines, every project is different and it is important to provide illustrative instances where the situation at hand may require a deviation from the nominal process. The lesson, of course, is that all design processes are useful as guides but should be constantly evaluated and perhaps tailored to avoid slavish adherence to process. It is not unusual to see engineering teams rigorously follow a process when a slight alteration could shorten the design cycle without any detrimental effect to the project itself.

After many years as an engineer and engineering manager working for NASA in the space program, it became clear that too many practicing engineers either don't have a clear idea of the traditional systematic approach to project design, or view it as an onerous process managed by inflexible non-stakeholders who they believe are more interested in executing the process successfully than completing the project successfully. Occasionally this is true, even of those in control of projects. In general, there is a credibility gap between those who understand, and believe in, the standard system engineering approach and those who would rather trust their instinct and juggle all of the issues real time without the benefit of an organized structure. There are many examples where the "instinctual" approach was successful. But, as engineering projects become increasingly complex and include multiple organizations, or even international partners, the task surpasses human capacity to be cognizant of all areas of the project. Furthermore, the unfortunate side effects of this kind of management can include cost overruns, schedule slips, restarts, gold plating, etc. Consequently, a well ordered systems engineering approach to a project which must meet a set of requirements and perform a given 
task, should be considered as fundamental knowledge which all student engineers should learn. Robert Ryan, a very experienced and highly regarded systems engineer formerly of the Marshall Space Flight Center explains the space exploration challenge this way, "The challenge of space flight is to conceive, design, build, and operate safely, high performance, high power density, highly interactive Space Systems at reasonable cost and schedule efficiency". This can only be achieved through the application of a thoughtful, logical, and consistent engineering process. A capstone design class that follows sound Systems Engineering and Project Management practices will more thoroughly prepare students for work in the commercial/industrial environment.

\section{Background}

As engineering students navigate their way through their undergraduate years, they are exposed to the various technological aspects of the particular engineering specialty they have chosen to pursue. While there is a growing effort to include more team projects in the first three years of undergraduate engineering education, by and large, the traditional curriculum is arranged such that courses are focused on narrow technical subjects in an order of increasing sophistication. The students learn how to solve engineering problems of increasing complexity as well as increasing specialty. The Capstone Design class provides an opportunity to exercise the students' skills in three fundamental areas: 1) students must be able to apply their technical skills to a real problem, 2) they must work as a member of a team, and 3) they must apply a traditional systems engineering process to the design function. In the final analysis, the Capstone Design course is an opportunity to wrap up the undergraduate engineering experience by teaching students how to be engineers in today's world. Not only is it important that they be prepared technically, but that they also understand the environment in which they will be expected to function.

There are innumerable books and academic papers providing guidance, instruction, and training in the art of Systems Engineering and Project Management and their application to the execution of project design. Typically, most engineering curricula do not specifically provide instruction in Systems Engineering or Project management. The Capstone Design class, however, is the ideal context for exposing the student to the art of Project Management and System Engineering. The challenge is how to teach enough System Engineering principles to be of value and still accomplish the other goals of most Capstone Design courses: teamwork, design, testing, fabrication - insofar as it is possible - and presentation of results.

At Texas A\&M there are currently three design tracks that students can choose from when registering for their senior design class: Aircraft Design, Rocket Design, and Spacecraft Design. In the fall of 2012 a fourth track will be added to encompass Rotorcraft Design. Note that the all three tracks follow a similar philosophy, but the discussion herein is limited strictly to the Spacecraft Design track.

A graphic representation of the relationship between System Engineering, Project Management, and Technical Integration ${ }^{1}$ as taught in the Spacecraft Capstone Design Class in the Aerospace Engineering Department at Texas A\&M University is shown below in Figure 1. 
A few comments must be made regarding Figure 1. First of all, this formulation is neither unique nor the only option for integrating the various functions necessary to manage an engineering project. It was, however, developed by the previously mentioned Mr. Robert Ryan and has been utilized successfully. It is also necessary to point out that this is just one of the many responsibilities of the Project Manager; however, from an educational point of view, attempting to cover too many aspects of any single responsibility is neither possible nor desirable. Not every student will become a project manager and it is more important to provide a thorough overview than a detailed study of just one function. Finally, the first two boxes on the left (Classical Systems Engineering and Design and Analytical Integration) are the primary focus of the design class under discussion. Interface Management, Verification, and Validation receive some attention, but not in depth.

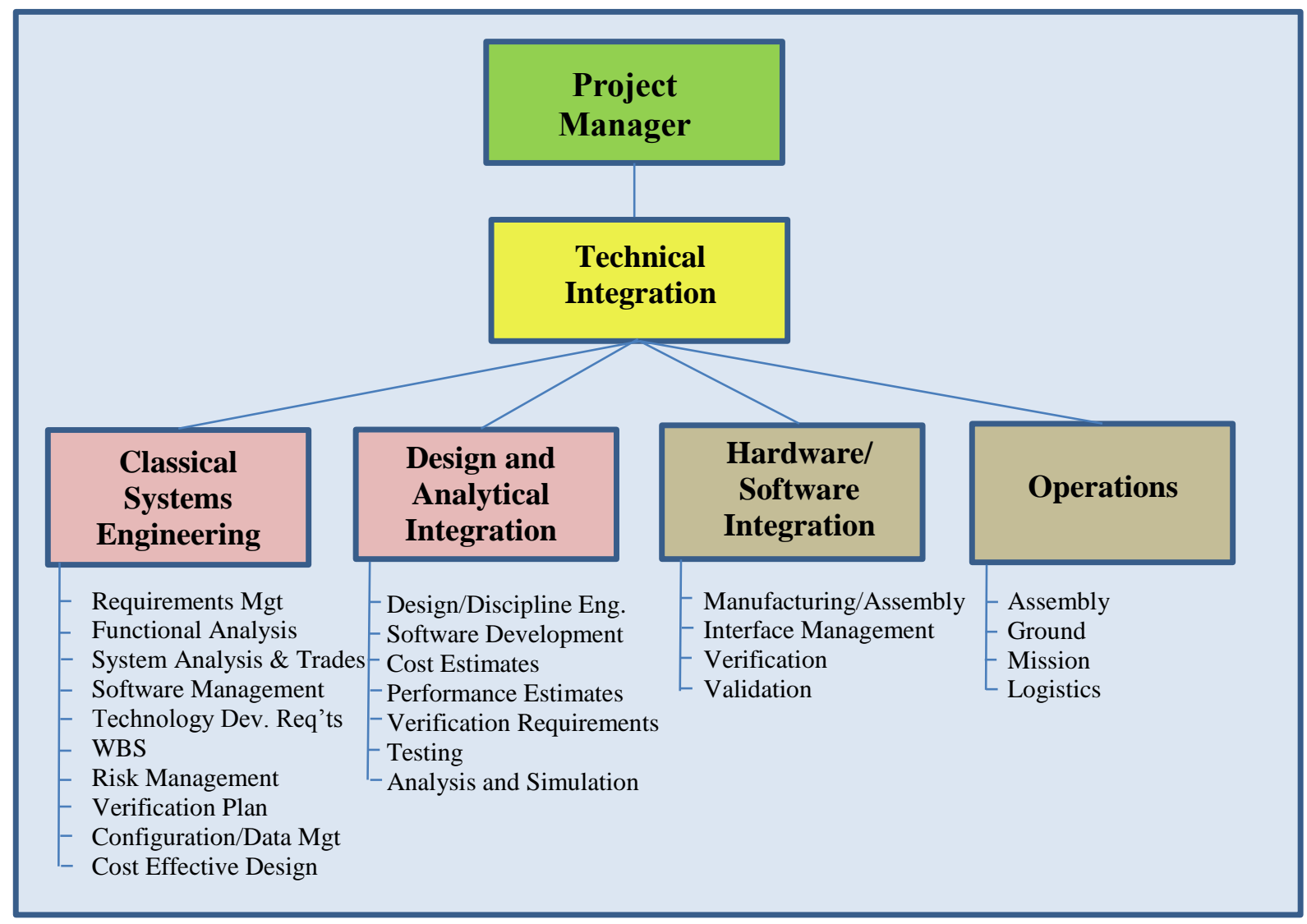

Figure 1 - Technical Integration Model

Contemporary engineering students at the fourth year level tend to be very competent in the application of their problem solving skills. Additionally, working in groups is not an issue for the current generation of students. They are connected socially in almost every conceivable 
way possible. They are in constant in communication with each other and, in many cases, work better together than alone. There is a difference, however, between working in groups and teamwork. Teamwork requires the performance of a task - often over a significant time span - independent of the team personalities. While occasionally difficult, it is constructive to let the team leader and the team work out these problems instead of manipulating team membership or commanding compliance in order to smooth out relationships. In the work place, they will not have the luxury of choosing their own teams and those in charge will only be interested in the results produced by the team, not whether the team got along in the process.

\section{Conceptual Design Phase}

In the Aerospace Engineering Department at Texas A\&M, the Capstone Design class is a two semester cycle. A semester sounds like a long period of time; however, it consists only of about 14 weeks. Thus, the dilemma faced by the instructor is how to provide a substantive design experience utilizing the principles of Systems Engineering and Project Management without diving too deeply into any one area and yet, covering the major topics well enough to prepare the students for the work environment. Toward that end, the first semester typically provides the foundational principles the student teams will use to produce their design at the completion of the second semester.

Initially, the first semester is relatively heavy in terms of lectures, discussions, and developmental assignments designed to provide the students with the fundamental principles of System Engineering, Project Management, the Project Life Cycle, and the tools of Project Design including such topics as requirements definition, concept of operations, work breakdown structure, schedule management, and configuration management. Covering requirements definition alone (as well as how to write a good requirement) could consume a significant amount of class time. Each instructor must determine which topics are the most important for that class and the depth of coverage required.

As the fundamentals are being introduced, the student teams are provided with a Mission Statement describing the project objectives and performance standards their design will have to satisfy. This signifies the beginning of the design process where the teams can begin to apply the processes and tools they have learned to the design of an actual spacecraft. To expedite the process, Pre-Phase A and Phase A are combined into one phase; the Concept Studies and Technology Development Phase (see Figure 2) ${ }^{2}$. This is more efficient yet does not sacrifice the effectiveness of the exercise. It is at this point that the student teams begin to be treated, as much as possible, as commercial engineering teams. In this capacity, the instructor takes on the role of Program Manager or Customer. The teams are allowed to utilize some class time to work on their designs according to the processes and are required to report in class weekly on their progress and issues. Each team operates independently and each team design represents an alternate solution to the same project objective as laid out in the Mission Statement.

During the Pre-Phase A/Phase A stage, there are three major reviews: 1) Mission Concept Review (MCR), 2) System Requirements Review (SRR) and 3) Mission Definition Review (MDR). The MCR is a review of the needs, goals, and objectives of the mission to ensure that 
any proposed concepts are at least feasible. The SRR will examine the functional and performance requirements of the project and ensure that the design concept will be able to perform the mission as outlined in the Mission Statement. The MDR occurs toward the end of this phase and is intended to ensure that the requirements, the mission architecture, and the design elements of the overall concept are capable of accomplishing the mission as outlined in the Mission Statement. To heighten reality, at the MDR, the student teams present their work to a review board consisting of engineers with relevant expertise. The review board asks questions and provides constructive criticism as well as positive reinforcement as appropriate. Upon successful completion of the MDR, the project enters Phase B of the flow process.

It has been found to be profitable to bring guest experts from industry to the class to lecture on specific areas, especially those that may not be covered in detail, if at all, during the student's undergraduate years. This would include such topics as integrating guidance with navigation and control; an introduction to autonomous systems; or the issues involved with rendezvous and docking between two independent spacecraft. Hearing from practicing engineers provides the students with a window into the engineering world and can be inspirational to realize that these engineers were once in their place. It is also very exciting to make a field trip to a nearby industrial or NASA facility at least once during every semester. Of course, this can be a problem for the instructor if there are no appropriate nearby facilities; but almost any engineering company can be interesting and most are more than happy to show students what they do.

As illustrated in Figure 2, Phase B is defined as the Preliminary Design and Technology Completion phase. It is very important to complete this phase before the end of the first semester. During this phase a complete set of system and subsystem design specifications are developed. The top level requirements and the flow down of requirements are typically finalized in Phase B and usually placed under configuration control. The primary effort, however, is developing a preliminary design solution that satisfies mission goals and objectives. At the end of Phase B, a Preliminary Design Review (PDR) is held. Each student team will again make a comprehensive presentation describing their design rationale to a board of experienced engineers. They will be expected to present their system design in a logical and coherent manner and answer questions posed by the review board. This is the end of the first semester of the Capstone Design Course. At the beginning of the next semester, the student teams will move on to Phase C, Final Design and Fabrication.

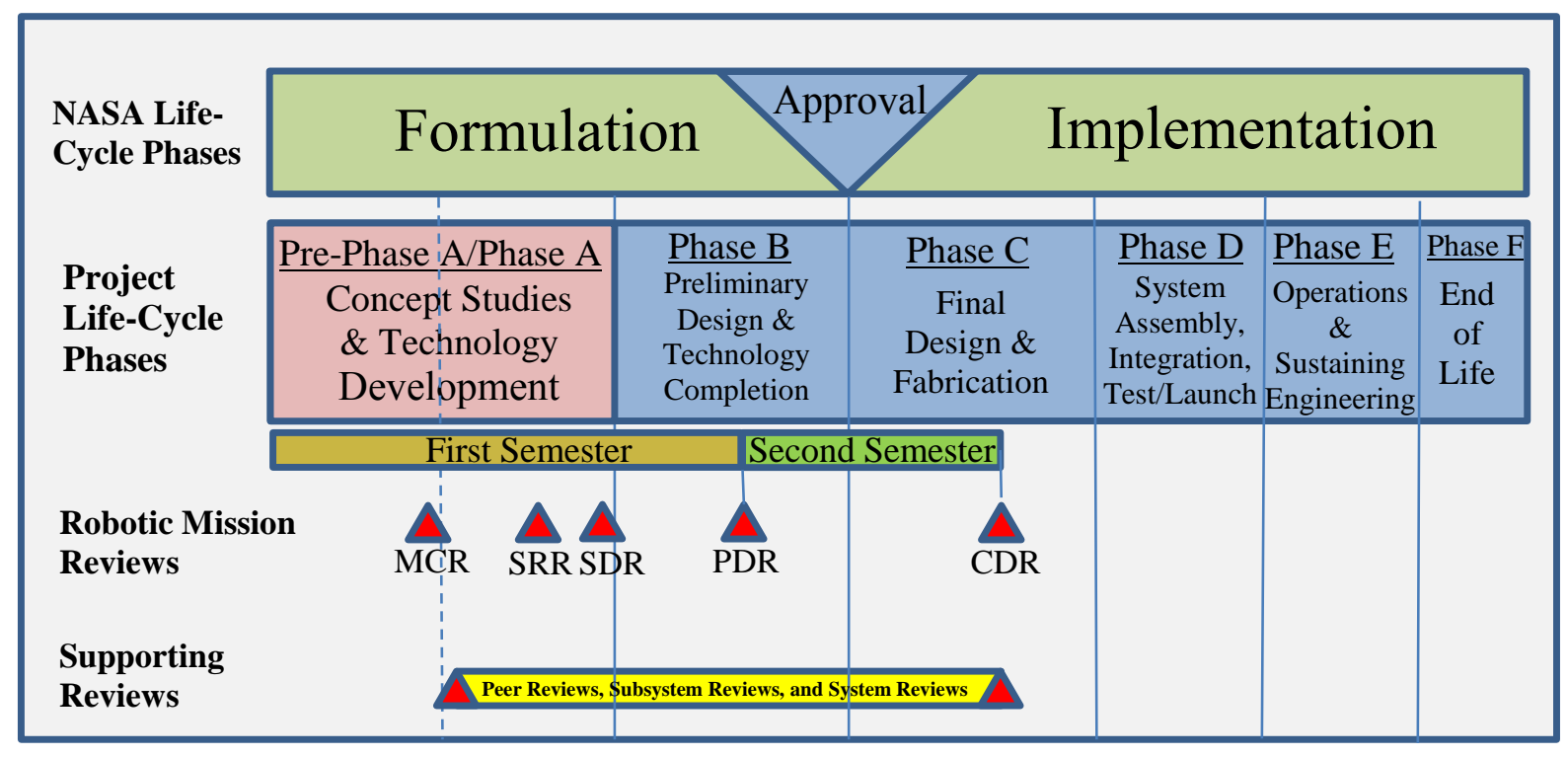




\section{Final Design Phase}

During the second semester, as the teams enter the Phase $\mathrm{C}$ activities, there is an expectation by the students of more hands-on activities. In the Aircraft Design Class and the Rocket Design Class, the second semester is where the student teams build models of their first semester design and then fly them to test the design. For the Spacecraft Design Class, however, it isn't possible to build and fly the student designs. There is absolutely no feasible way to either build or launch a spacecraft during the semester (or even the year). Nevertheless, during the second semester, it is critical that the design process include some "hands-on" activities, not to compete with the other design classes, but to extract valuable design lessons. For example, foam core mockups can be useful in visualizing spatial relationships. A range of activities from simple test demonstrations to more complex simulations all serve to establish a link in the mind between analysis and the real world. However, if the students expect to find a close correlation between their analytical results and their tests and simulations, they are generally disappointed; thus providing a valuable lesson: analysis and the associated test simulation may not match well - if at all. But, the value stems from discerning why they don't match. Initially, the student may view the mismatch as a failure, but it is crucial that they learn that failure is a better teacher than success.

In addition, the students are encouraged to build prototypes of mechanisms or develop simple tests of the pass/fail variety to prove the feasibility of an idea or concept. Students are typically optimistic regarding their designs; however, it is critical that they test their designs. Quite often they discover that something was overlooked. This can be a valuable lesson.

As in the first semester, guest lecturers and field trips are activities that the students not only enjoy, but are both instructional and inspirational. It is also useful, but not crucial, if the guest lecturers are within five or six years of graduation. The students can easily identify with them and are more likely to engage them in conversation and ask questions. If at all possible, it is important to include female, male, and minority guest lecturers. Every student should be able

to see themselves in the guest. While field trips can be logistically difficult, getting to look behind the scenes at an engineering organization can be extremely inspirational for the students and is therefore, worth the logistical difficulties.

\section{CONCLUSIONS}

Technical capability has always been, and will continue to be a desirable and sought after attribute in graduate engineers. Companies obviously want their engineers to be as competent 
as possible and it has become common for companies to require a minimum grade point average (GPA) in order to qualify for hiring consideration. While a good GPA is important, knowledge of the principles of System Engineering and Project Management should not be overlooked. Conversely, depending solely on processes can lead to process slavery in which the alleged object of the process, the product, almost becomes irrelevant. By teaching a balance of technical expertise and Systems Engineering, the engineering graduates of tomorrow will be better equipped to design and build superior products on schedule and within cost.

Bibliography

1. Robert Ryan, Presentation entitled "Technical Integration", March, 2011

2. NASA Systems Engineering Handbook, NASA/SP-2007-6105 Rev1 